\title{
Expanding the applicability of secant-like methods for solving nonlinear equations
}

\section{K. Argyros, J. A. EzQuerro, M. A. Hernández, S. Hilout, N. Romero and A. I. VELASCO}

\section{ABSTRACT.}

We use the method of recurrent functions to provide a new semilocal convergence analysis for secant-like methods in order to approximate a locally unique solution of a nonlinear equation in a Banach space setting. Our sufficient convergence criteria are weaker than in earlier studies such as [18, 19, 20, 21, 25, 26]. Therefore, the new approach has a larger convergence domain and uses the same constants. A numerical example involving a nonlinear integral equation of mixed Hammerstein type is given to illustrate the advantages of the new approach. Another example of nonlinear integral equations is presented to show that the old convergence criteria are not satisfied but the new convergence are satisfied.

\section{REFERENCES}

[1] Amat, S., Busquier, S. and Negra, M., Adaptive approximation of nonlinear operators, Numer. Funct. Anal. Optim., 25 (2004), 397-405

[2] Argyros, I. K., Polynomial Operator Equations in Abstract Spaces and Applications, St.Lucie/CRC/Lewis Publ. Mathematics series, 1998, Boca Raton, Florida, USA

[3] Argyros, I. K., On the Newton-Kantorovich hypothesis for solving equations, J. Comput. Appl. Math., 169 (2004), 315-332

[4] Argyros, I. K., A unifying local-semilocal convergence analysis and applications for two-point Newton-like methods in Banach space, J. Math. Anal. Appl., 298 (2004), 374-397

[5] Argyros, I. K., New sufficient convergence conditions for the secant method, Chechoslovak Math. J., 55 (2005), 175-187

[6] Argyros, I. K., Convergence and Applications of Newton-type Iterations, Springer-Verlag Publ., New-York, 2008

[7] Argyros, I. K., Approximating solutions of equations using Newton's method with a modified Newton's method iterate as a starting point, Rev. Anal. Numér. Théor. Approx., 36 (2007), 123-138

[8] Argyros, I. K., A semilocal convergence analysis for directional Newton methods, Math. Comput., 80 (2011), 327-343

[9] Argyros, I. K., Cho, Y. J. and Hilout, S., Numerical Methods for Equations and its Applications, CRC Press/Taylor and Francis, Boca Raton, Florida, USA, 2012

[10] Argyros, I. K. and Hilout, S., Convergence conditions for secant-type methods, Chechoslovak Math. J., 60 (2010), 253-272

[11] Argyros, I. K. and Hilout, S., Weaker conditions for the convergence of Newton's method, J. Complexity, 28 (2012), 364-387

[12] Argyros, I. K. and Hilout, S., Estimating upper bounds on the limit points of majorizing sequences for Newton's method, Numer. Algorithms, 62 (2013), 115-132

[13] Argyros, I. K. and Hilout, S., Computational methods in nonlinear analysis. Efficient algorithms, fixed point theory and applications, World Scientific, to appear in 2013

[14] Bosarge, W. E. and Falb, P. L., A multipoint method of third order, J. Optimiz. Th. Appl., 4 (1969), 156-166

Received: 12.04.2013; In revised form: 02.04.2014; Accepted: 23.04.2014

2010 Mathematics Subject Classification. 65H10, 65G99, 47H99, 49M15.

Key words and phrases. Banach space, Secant-like methods, Newton's method, the secant method, majorizing sequence, semilocal convergence, divided difference operator, Fréchet-derivative.

Corresponding author: M. A. Hernández-Verón; mahernan@unirioja.es 
[15] Cianciaruso, F., Convergence theorems for Newton-like methods for operators with generalized Hölder derivative, Fixed Point Theory, 5 (2004), 21-35

[16] Dennis, J. E., Toward a unified convergence theory for Newton-like methods, in Nonlinear Functional Analysis and Applications (L.B. Rall, ed.), Academic Press, New York, (1971), 425-472

[17] Ezquerro, J. A., Gutiérrez, J. M., Hernández, M. A., Romero, N. and Rubio, M. J., The Newton method: from Newton to Kantorovich. (Spanish), Gac. R. Soc. Mat. Esp., 13 (2010), 53-76

[18] Ezquerro, J. M., Hernández, M. A., Romero, N. and Velasco, A. I., Improving the domain of starting point for secant-like methods, Appl. Math. Comput., 219 (2012), 3677-3692

[19] Ezquerro, J. A. and Rubio, M. J., A uniparametric family of iterative processes for solving nondifferentiable equations, J. Math. Anal. Appl, 275 (2002), 821-834

[20] Hernández, M. A., Rubio, M. J. and Ezquerro, J. A., Secant-like methods for solving nonlinear integral equations of the Hammerstein type, Proceedings of the 8th International Congress on Computational and Applied Mathematics, ICCAM-98 (Leuven), J. Comput. Appl. Math., 115 (2000), 245-254.

[21] Hernández, M. A., Rubio, M. J. and Ezquerro, J. A., Solving a special case of conservative problems by secant-like methods, Appl. Math. Comput., 169 (2005), 926-942

[22] Kantorovich, L. V. and Akilov, G. P., Functional Analysis, Pergamon Press, Oxford, 1982

[23] Laasonen, P., Ein überquadratisch konvergenter iterativer algorithmus, Ann. Acad. Sci. Fenn. Ser I, 450 (1969), $1-10$

[24] Ortega, J. M. and Rheinboldt, W. C., Iterative Solution of Nonlinear Equations in Several Variables, Academic Press, New York, 1970

[25] Potra, F. A., Sharp error bounds for a class of Newton-like methods, Libertas Mathematica, 5 (1985), 71-84

[26] Potra, F. A. and Pták, V., Nondiscrete Induction and Iterative Processes, Pitman, New York, 1984

[27] Proinov, P. D., General local convergence theory for a class of iterative processes and its applications to Newton's method, J. Complexity, 25 (2009), 38-62

[28] Proinov, P. D., New general convergence theory for iterative processes and its applications to Newton-Kantorovich type theorems, J. Complexity, 26 (2010), 3-42

[29] Schmidt, J. W., Untere Fehlerschranken fur Regula-Falsi Verhafren, Period. Hungar., 9 (1978), 241-247

[30] Traub, J. F., Iterative Methods for the Solution of Equations, Prentice-Hall, Englewood Cliffs, New Jersey, 1964

[31] Yamamoto, T., A convergence theorem for Newton-like methods in Banach spaces, Numer. Math., 51 (1987), $545-557$

[32] Wolfe, M. A., Extended iterative methods for the solution of operator equations, Numer. Math., 31 (1978), $153-174$

\author{
Department OF MATHEMATics SCiEnCES \\ CAMERON UNIVERSITY \\ LAWTON, OK 73505, USA \\ E-mail address: iargyrosecameron.edu
}

\title{
DEPARTMENT MATHEMATICS AND COMPUTATION \\ UNIVERSITY OF LA RIOJA \\ 26004 LOGROÑO, SPAIN \\ E-mail address: jezquer@unirioja.es \\ E-mail address: mahernan@unirioja.es \\ E-mail address: natalia.romero@unirioja.es \\ E-mail address: anabelmates@hotmail.com.ar
}

POITIERS UNIVERSITY

Laboratoire De Mathématiques et Applications

86962 Futuroscope Chasseneuil Cedex, France

E-mail address: said.hilout@math.univ-poitiers.fr 